\title{
Instrumental variability of respiratory blood gases among different blood gas analysers in different laboratories
}

\author{
M.J. Kampelmacher*, R.G. van Kesteren*, E.K.A. Winckers**
}

Instrumental variability of respiratory blood gases among different blood gas analysers in different laboratories. M.J. Kampelmacher, R.G. van Kesteren, E.K.A. Winckers. (C)ERS Journals Ltd 1997.

ABSTRACT: The aim of this study was to test the hypothesis that differences in oxygen tension $\left(\mathrm{PO}_{2}\right)$ and carbon dioxide tension $\left(\mathrm{P}_{\mathrm{CO}}\right)$ values from measurements performed on different blood gas analysers in different laboratories are clinically insignificant.

Samples of fresh whole human tonometered blood $\left(\mathrm{PO}_{2} 8.1 \mathrm{kPa}(60.8 \mathrm{mmHg})\right.$; $\mathrm{PCO}_{2} 5.3 \mathrm{kPa}(39.9 \mathrm{mmHg})$ ) were placed in airtight glass syringes and transported in ice-water slush. Blood gas analysis was performed within $3.5 \mathrm{~h}$ by 17 analysers (10 different models) in 10 hospitals on one day.

The mean of the differences between the measured and target values was $\mathbf{- 0 . 0 1 \pm}$ 0.19 and $0.21 \pm 0.13 \mathrm{kPa}(-0.06 \pm 1.45$ and $1.55 \pm 1.01 \mathrm{mmHg})$ for $\mathrm{PO}_{2}$ and $\mathrm{PCO}_{2}$, respectively. The mean of the differences between two samples on one analyser was $0.06 \pm 0.06$ and $0.04 \pm 0.03 \mathrm{kPa}(0.47 \pm 0.48$ and $0.29 \pm 0.24 \mathrm{mmHg})$, respectively. For $\mathrm{PO}_{2}$ and $\mathrm{PCO}_{2}$ the interinstrument standard deviations $\left(\mathrm{s}_{\mathrm{b}}\right)$ were 0.18 and $0.13 \mathrm{kPa}$ (1.38 and $0.99 \mathrm{mmHg}$ ), respectively, whereas the intra-instrument standard deviations (s) were 0.06 and $0.03 \mathrm{kPa}(0.47$ and $0.26 \mathrm{mmHg})$, respectively. Both for $\mathrm{PO}_{2}$ and $\mathrm{PCO}_{2}$ the ratios of $\mathrm{s}_{\mathrm{b}}{ }^{2}$ and $\mathrm{s}^{2}$ were statistically significant (analysis of variance $(A N O V A) p<0.001)$. The standard deviations of a random measurement on a random analyser were 0.19 and $0.14 \mathrm{kPa}(1.46$ and $1.02 \mathrm{mmHg})$ for $\mathrm{PO}_{2}$ and $\mathrm{PCO}_{2}$, respectively.

We conclude that the variability in measurement of blood gas values among different blood gas analysers, although negligible, depends much more on inter- than intra-instrument variation, both for oxygen tension and carbon dioxide tension. Technical improvements and adequate quality control programmes, including tonometry, may explain why the variability in blood gas values depends mainly on errors in the pre-analytical phase. Eur Respir J 1997; 10: 1341-1344.
*Centre for Home Mechanical Ventilation, Division of Internal Medicine and Dermatology and **Dept of Clinical Chemistry, University Hospital Utrecht, Utrecht, The Netherlands.

Correspondence: M.J. Kampelmacher University Hospital Utrecht

Centre for Home Mechanical Ventilation HP B00. 118

P.O. Box 85500

3508 GA Utrecht

The Netherlands

Received: August 51996

Accepted after revision February 231997

Keywords: Blood gas analysis

reproducibility

respiratory

tonometry

variability

This study was supported by a research grant (No. 28-1721) of the Dutch Praeventiefonds.
Blood gas analysis is frequently employed in clinical care and research. Arterial oxygen tension $\left(\mathrm{Pa}_{\mathrm{a}} \mathrm{O}_{2}\right)$ and carbon dioxide tension $\left(\mathrm{Pa}_{\mathrm{a}}, \mathrm{CO}_{2}\right)$ are frequently used as selection criteria, indices of assessment or endpoints [1-6]. If only one blood gas analyser (BGA) is used, the $P \mathrm{a}, \mathrm{O}_{2}$ and $\mathrm{Pa}_{\mathrm{a}} \mathrm{CO}_{2}$ values reflect the specific performance characteristics of that particular BGA. Although there may be bias (the systematic tendency to over- or underestimate), precision (a measure of reproducibility) is usually excellent $[7,8]$. However, if analyses are performed in different BGAs, as often happens in multicentre studies and with patients involved in home care programmes, large differences in mean values and standard deviations, as well as conflicting results, may arise, particularly for oxygen tension $\left(\mathrm{P}_{2}\right)$. Manufacturer- and model-specific design and performance characteristics apparently affect the accuracy of the measurement [7-10]. If BGA-specific differences in bias or precision exist, there may be both statistically and clinically significant differences between values obtained by different BGAs. Consequently, research and clinical conclusions may be influenced by the performance characteristics of the BGA models employed.

This study was designed to test the hypothesis that the instrumental variability of respiratory blood gas values is negligible, such that differences in $\mathrm{PO}_{2}$ and carbon dioxide tension $\left(\mathrm{PCO}_{2}\right)$ measurements performed using different BGAs in different laboratories are clinically insignificant.

\section{Methods}

\section{Instruments and materials}

Fresh venous blood was used, drawn from one volunteer (MJK) into heparinized collecting tubes. Aliquots of $20 \mathrm{~mL}$ blood were equilibrated in a Laué tonometer (Eschweiler and Co., Kiel, Germany) for at least $30 \mathrm{~min}$, with a prehumidified gas mixture containing $8.54 \%$ oxygen, $5.61 \%$ carbon dioxide and nitrogen to $100 \%$ by 
volume (from Hoek Loos, Amsterdam, The Netherlands). Both tonometer and humidifier were submerged in a water bath, maintained at $37^{\circ} \mathrm{C}$. Tonometered samples were removed anaerobically from the tonometer into two airtight glass syringes (Hamilton, Banaduz AG, Switzerland), which were immediately capped and put into a box with crushed ice. The partial gas pressures of oxygen $\left(\mathrm{PO}_{2} 8.1 \mathrm{kPa}(60.79 \mathrm{mmHg})\right)$ and carbon dioxide $\left(P_{\mathrm{CO}_{2}} 5.3 \mathrm{kPa}(39.94 \mathrm{mmHg})\right)$ were calculated by multiplying the barometric pressure minus the pressure of water vapour $\left(6.3 \mathrm{kPa}(47 \mathrm{mmHg})\right.$ at $\left.37^{\circ} \mathrm{C}\right)$ by the volume fraction of the respective gas.

\section{Protocol}

Blood samples from the glass syringes were measured successively in 10 different hospitals. Three hospitals used more than one BGA. This procedure was performed twice on the same day. Five hospitals were visited during the first round and four hospitals during the second. The first and final measurements of each round were performed in the clinical laboratory of our hospital. The other hospitals, which were located within a distance of $20 \mathrm{~km}$, were then visited. Each round took less than 3.5 h. In each BGA, two measurements were performed. All samples were injected into the instruments by experienced laboratory technicians, who were told that the samples were part of a research study. Barometric pressure was taken from the latest calibration printout. Each BGA was deemed to be operating properly in accordance with the laboratory's quality-control procedures, before each pair of samples was introduced. As this study was designed explicitly to assess the performance of BGAs under normal operating conditions, each pair of samples was interspersed by clinical specimens, and among regularly scheduled calibration and/or quality control procedures. No other procedures of this kind were performed and no measurement was preceded by such a procedure.

\section{Statistical analysis}

The data are expressed as mean \pm standard deviation (SD). "Deltas" $\left(\delta \mathrm{t} \mathrm{PO}_{2}\right.$ and $\left.\delta \mathrm{t} P \mathrm{CO}_{2}\right)$ are the differences between the measured values of the samples and the target values (t) for $P_{\mathrm{O}_{2}}$ and $P_{\mathrm{CO}_{2}}$. Bias was defined as the mean difference between the BGA-determined $\mathrm{PO}_{2}$ and the $\mathrm{t}_{\mathrm{O}_{2}}$ value, or between the BGA-determined $P_{\mathrm{CO}_{2}}$ and the $\mathrm{t}_{\mathrm{CO}_{2}}$ value. Precision was defined as the differences of the $\mathrm{PO}_{2}$ and $\mathrm{PCO}_{2}$ values between two samples measured in the same BGA. Both bias and precision were examined according to ScUDERI et al. [7]. Analysis of variance (ANOVA) was used to discriminate between inter- and intra-analyser variability. A p-value of less than 0.05 was considered to be significant.

\section{Results}

Using 17 BGAs (four different types; 10 different models) in 10 hospitals, a total of 34 measurements was performed. The overall means of $\delta \mathrm{t} \mathrm{PO}_{2}$ and $\delta \mathrm{t} P \mathrm{PO}_{2}$ were $-0.01 \pm 0.19(-0.31-0.29)$ and $0.21 \pm 0.13(-0.03-0.41) \mathrm{kPa}$
Table 1. - Mean deviations of instrument $\mathrm{PO}_{2}$ and $\mathrm{PCO}_{2}$ values from tonometry target values

\begin{tabular}{|c|c|c|c|c|c|}
\hline & \multicolumn{2}{|c|}{$\mathrm{t} P \mathrm{O}_{2}$} & \multicolumn{2}{|c|}{$\mathrm{t} P \mathrm{CO}_{2}$} \\
\hline & & $\mathrm{kPa}$ & $\mathrm{mmHg}$ & $\mathrm{kPa}$ & $\mathrm{mmHg}$ \\
\hline \multicolumn{2}{|c|}{ Target value } & 8.1 & 60.79 & 5.3 & 39.94 \\
\hline $\begin{array}{l}\text { Hospital } \\
\text { No. }\end{array}$ & Instrument & & & & \\
\hline 1 & ABL3 (A) & -0.16 & -1.19 & -0.03 & -0.24 \\
\hline 1 & ABL3 (B) & -0.02 & -0.14 & +0.37 & +2.81 \\
\hline 1 & ABL3 (C) & -0.16 & -1.24 & +0.07 & +0.56 \\
\hline 1 & ABL3 (D) & +0.05 & +0.36 & +0.27 & +2.06 \\
\hline 1 & ABL-330 & -0.21 & -1.59 & +0.23 & +1.76 \\
\hline 1 & Corning 288 & -0.18 & -1.39 & +0.17 & +1.26 \\
\hline 2 & Corning 178 & -0.20 & -1.54 & +0.01 & +0.06 \\
\hline 3 & AVL947 & -0.30 & -2.29 & +0.33 & +2.51 \\
\hline 4 & Corning 178 & -0.03 & -0.24 & +0.24 & +1.81 \\
\hline 5 & Corning 178 & +0.12 & +0.93 & +0.15 & +1.11 \\
\hline 6 & IL1312 & +0.08 & +0.63 & +0.30 & +2.26 \\
\hline 7 & IL1306 (E) & +0.16 & +1.21 & +0.21 & +1.56 \\
\hline 7 & IL1306 (F) & +0.16 & +1.21 & +0.25 & +1.91 \\
\hline 8 & IL1302 & -0.20 & -1.49 & +0.03 & +0.21 \\
\hline 9 & ABL300 & +0.23 & +1.71 & +0.37 & +2.76 \\
\hline 9 & IL1301 & +0.29 & +2.21 & +0.12 & +0.91 \\
\hline 10 & ABL30 & +0.22 & +1.66 & +0.41 & +3.06 \\
\hline Mean & & -0.01 & -0.06 & +0.21 & +1.55 \\
\hline SD & & \pm 0.19 & \pm 1.45 & \pm 0.13 & \pm 1.01 \\
\hline
\end{tabular}

$\mathrm{PO}_{2}$ : oxygen tension; $\mathrm{PCO}_{2}$ : carbon dioxide tension; $\mathrm{tPO}_{2}$ : target oxygen tension; $\mathrm{t}_{\mathrm{CO}_{2}}$ : target carbon dioxide tension. The ABL instruments were manufactured by Radiometer, Copenhagen, Denmark; Corning instruments by Ciba-Corning, Ameryville, CA, USA; IL instruments by Instrument Laboratories, Milan, Italy; and the AVL 947 by AVL Medical Instruments AG, Schaffhausen, Switzerland.

$(-0.06 \pm 1.45$ (range $-2.29-2.21)$ and $1.55 \pm 1.01(-0.24-3.06)$ $\mathrm{mmHg}$ ), respectively (table 1 ). The overall means of the absolute values of $\delta \mathrm{t} P \mathrm{O}_{2}$ and $\delta \mathrm{t} P \mathrm{CO}_{2}$ were 0.17 and 0.21 $\mathrm{kPa}(1.24$ and $1.58 \mathrm{mmHg})$, respectively. The means of the differences between two measurements in one BGA were $0.06 \pm 0.06(0-0.20)$ and $0.04 \pm 0.03(0-0.12) \mathrm{kPa}$ $(0.47 \pm 0.48(0-1.50)$ and $0.29 \pm 0.24(0-0.90) \mathrm{mmHg})$ for $\mathrm{PO}_{2}$ and $\mathrm{PCO}_{2}$, respectively.

For $\mathrm{PO}_{2}$ and $\mathrm{PCO}_{2}$ the interinstrument standard deviations $\left(\mathrm{s}_{\mathrm{b}}\right)$ were 0.18 and $0.13 \mathrm{kPa}(1.38$ and $0.99 \mathrm{mmHg}$ ), respectively, whereas the intra-instrument standard deviations (s) were 0.06 and $0.03 \mathrm{kPa}(0.47$ and $0.26 \mathrm{mmHg})$, respectively. For both $\mathrm{PO}_{2}$ and $\mathrm{PCO}_{2}$, the ratios of $\mathrm{s}_{\mathrm{b}}{ }^{2}$ and $s^{2}$ were statistically significant $(\mathrm{p}<0.001)$. The overall SD $\left(\mathrm{s}_{\mathrm{t}}\right)$ values of random measurements in a random BGA, were 0.19 and $0.14 \mathrm{kPa}(1.46$ and $1.02 \mathrm{mmHg}$ ) for $\mathrm{PO}_{2}$ and $\mathrm{PCO}_{2}$, respectively. Because $\mathrm{s}$ was much

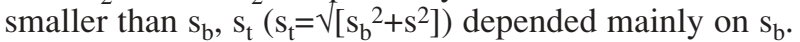

\section{Discussion}

The purpose of this study was to test the reproducibility of a single blood gas measurement in a random BGA in any hospital in the Netherlands under routine clinical conditions. We were not interested in the bias of each BGA, but in the variability (standard deviation) between the BGAs tested. Our results show that this variability is clinically insignificant, both for $\mathrm{PO}_{2}$ and $P_{\mathrm{CO}_{2}}$. This study was part of a multicentre study on longterm oxygen therapy, in which $P \mathrm{a}, \mathrm{O}_{2}<8.0 \mathrm{kPa}(60 \mathrm{mmHg})$ 
is used as a selection criterion. If significant variability between the blood gas values of the different BGAs could be demonstrated, we might have been forced to demand that the $P \mathrm{a}, \mathrm{O}_{2}$ of all patients was measured in our hospital before a patient could enter the study. However, on the basis of our results there was no reason for such a requirement.

The findings of this study are in agreement with two studies that compared BGA accuracy for $P_{\mathrm{O}_{2}}$ or $P_{\mathrm{CO}_{2}}$ with a common source of tonometered blood, and which found small differences between BGA means [9, 11]. The good within-instrument precision for both $\mathrm{PO}_{2}$ and $\mathrm{PCO}_{2}$ is consistent with several previous studies, that have used repetitive and consecutive analysis of blood or quality-control solutions uninterrupted by clinical blood analyses [9, 12]. Nevertheless, our results are remarkable, all the more so because several studies comparing the measured tonometered $\mathrm{PO}_{2}$ values from BGAs of different makes indicate that, despite the fact that imprecision may be relatively small, significant differences in bias exist between analysers $[7,8,12]$.

There are analyser-specific factors that can influence accuracy, particularly for the measurement of $\mathrm{PO}_{2}$. The following instrument differences may all contribute to model-specific differences: sample size; sample introduction technique; sample warming; chamber rinsing; analysis time; chamber size; contamination from residual material within the measuring chamber prior to sample introduction (memory effect); inherent drift characteristics of the electrode; electrode signal processing; calibration methods; intra-instrument variation over time; and ease of instrument repair and maintenance [8-11]. Technical improvement of modern analysers and adequate quality-control programmes could explain why the variability among the different types of BGAs in our study was substantially lower than that previously reported in other proficiency programmes. Because the overall variability between BGAs was determined mainly by interinstrument variability, frequent calibration and quality control, including tonometry, are more important than repetitive measurements in the same BGA. In this study, tonometered blood was used because it is the technique for establishing the inaccuracy and imprecision of an individual BGA [8-13]. Tonometry of fresh heparinized whole blood instead of stored whole blood offers a more "physiological" method, since the material and, especially, the $\mathrm{PO}_{2}$ at which the haemoglobin is half saturated with oxygen (P50) are the same as in actual patient samples [9]. Moreover, by using tonometered blood, we tried to mimic the clinical setting as closely as possible.

Several factors may have decreased the variation between the BGAs tested. Firstly, only one target value was used. Moreover, at $P_{\mathrm{O}_{2}}$ levels $<8.0 \mathrm{kPa}(60 \mathrm{mmHg})$ differences between measured and tonometered $\mathrm{PO}_{2}$ values tend to be small [14]. At this low $\mathrm{PO}_{2}$, the dissociation of oxyhaemoglobin will stabilize the level of physically dissolved oxygen, which is the oxygen fraction measured by the electrode [15]. In contrast to the $P_{\mathrm{O}_{2}}$ values, $\delta \mathrm{t} P \mathrm{CO}_{2}$ is affected much less by the $P_{\mathrm{CO}_{2}}$ level [14]. Secondly, this study was undertaken on one particular day. Furthermore, all BGAs tested were located at virtually the same altitude and the samples were transported in two airtight glass syringes. Finally, imprecision might have been larger if more than two sam- ples had been measured by the same BGA. The samples were, however, measured under routine clinical conditions, which could potentially have increased overall variation [14]. In addition, tonometered samples were kept in ice-water slush for a considerable time. Although $P_{\mathrm{CO}_{2}}$ and $\mathrm{pH}$ values hardly change within $4 \mathrm{~h}$, theoretically $\mathrm{PO}_{2}$ values could have changed more than $2 \%$ [16-18]. The $\mathrm{PO}_{2}$ and $\mathrm{PCO}_{2}$ values measured by the same $\mathrm{BGA}$ at the beginning and at the end of every round, however, did not differ by more than 0.09 and $0.07 \mathrm{kPa}$ $(0.7$ and $0.5 \mathrm{mmHg})$, respectively.

Although pre-analytical errors cannot be ruled out completely, in this study, variability was affected predominantly by analytical errors. This is different from the situation in clinical practice where pre-analytical errors play a major role, especially for $\mathrm{PO}_{2}$. In the preanalytical phase, the blood gas results may be influenced, for example, by: the ventilatory status of the patient before and during blood collection; the blood $\mathrm{Po}_{2}$ level; the technique of specimen collection; the nature of the specimen container, preparation of the container with anticoagulant; sample handling; cooling of the sample; storage and transport of the specimen; and severe leucocytosis or thrombocytosis [16-26]. This study provides indirect support for the idea that standardization and quality control in the preanalytical phase represent the best strategy to optimize reproducibility of measurements of blood gas values in a clinical setting.

We conclude that the instrumental variability of blood gas values among different types and models of blood gas analysers in different laboratories depends much more on inter- than on intra-instrument variation, and is negligible, for both oxygen tension and carbon dioxide tension. High technical standards and adequate qualitycontrol programmes, including tonometry, may explain why the variability in blood gas values is related mainly to the pre-analytical phase.

Acknowledgements: The authors would like to thank Ir.S van Ooik and the staff of the Department of Clinical Chemistry, University Hospital Utrecht, for technical assistance.

\section{References}

1. Nocturnal Oxygen Therapy Trial Group. Continuous or nocturnal oxygen therapy in hypoxemic chronic obstructive lung disease: a clinical trial. Ann Intern Med 1980; 93: 391-398.

2. Fletcher EC, Donner C, Midgren B, et al. Survival in COPD patients with a daytime $P \mathrm{a}, \mathrm{O}_{2}>60 \mathrm{mmHg}$ with and without nocturnal oxyhemoglobin desaturation. Chest 1992; 101: 649-655.

3. Selinger SR, Kennedy TP, Buescher P, et al. Effects of removing oxygen from patients with chronic obstructive pulmonary disease. Am Rev Respir Dis 1987; 136 : 85-91.

4. Ström K, Pehrsson K, Boe J, Nachemson A. Survival of patients with severe thoracic spine deformities receiving domiciliary oxygen therapy. Chest 1992; 102: 164-168.

5. Bardsley PA, Howard P, Tang O, et al. Sequential treatment with low-dose almitrine bismesylate in hypoxaemic chronic obstructive airways disease. Eur Respir J 1992; 5: 1054-1061. 
6. O'Donohue W Jr. Effects of oxygen therapy on increasing arterial oxygen tension in hypoxemic patients with stable chronic obstructive pulmonary disease while breathing ambient air. Chest 1991; 100: 968-972.

7. Scuderi PE, MacGregor DA, Bowton DL, Harris LC, Anderson R, James RL. Performance characteristics and interanalyzer variability of $\mathrm{PO}_{2}$ measurements using tonometered human blood. Am Rev Respir Dis 1993; 147: 1354-1359.

8. Hansen JE, Feil MC. Blood gas quality control materials compared to tonometered blood in examining for interinstrument bias in $\mathrm{PO}_{2}$. Chest 1988; 94: 49-54.

9. Van Kessel AL, Eichhorn JH, Clausen JL, Stone ME, Rotman HH, Crapo RO. Interinstrument comparison of blood gas analyzers and assessment of tonometry using fresh heparinized whole human blood. Chest 1987; 92: 418-422.

10. Hansen JE, Casaburi R, Crapo RO, Jensen RL. Assessing precision and accuracy in blood gas proficiency testing. Am Rev Respir Dis 1990; 141: 1190-1193.

11. Hansen JE, Stone ME, Ong ST, Van Kessel AL. Evaluation of blood gas quality control and proficiency testing materials by tonometry. Am Rev Respir Dis 1982; 125: 480-483.

12. Sutt-Corbet B, Fonzi C. Instrumental biases in blood gas analysis of tonometered whole blood. Clin Chem 1982; 28: 550-552.

13. Teng Leary E, Delaney CJ, Kenny MA. Use of equilibrated blood for internal blood-gas quality control. Clin Chem 1977; 23: 493-503.

14. Hansen JE, Jensen RL, Casaburi R, Crapo RO. Comparison of blood gas analyzer biases in measuring tonometered blood and a fluorocarbon-containing, proficiency-testing material. Am Rev Respir Dis 1989; 140: 403-409.

15. Kofstad J. A comparison of four different blood gas analysers. Scand J Clin Lab Invest 1981; 41: 409-414.

16. Bageant RA. Variations in arterial blood gas measure- ments due to sampling techniques. Respir Care 1975; 20: $565-570$.

17. Madiedo G, Sciacca R, Hause L. Air bubbles and temperature effect on blood gas analysis. J Clin Pathol 1980; 33: 864-867.

18. Ishikawa S, Fornier A, Borst C, Segal MS. The effects of air bubbles and time delay on blood gas analysis. Ann Allergy 1974; 33: 72-77.

19. Mahoney JJ, Harvey JA, Wong RJ, Van Kessel AL. Changes in oxygen measurements when whole blood is stored in iced plastic or glass syringes. Clin Chem 1991; 37: 1244-1248.

20. Schmidt C, Müller-Plathe O. Stability of $\mathrm{PO}_{2}, \mathrm{PCO}_{2}$ and $\mathrm{pH}$ in heparinized whole blood samples: influence of storage temperature with regard to leukocyte count and syringe material. Eur J Clin Chem Clin Biochem 1992; 30: 767-773.

21. Hess CE, Nichols AB, Hunt WB, Suratt PM. Pseudohypoxemia secondary to leukemia and thrombocytosis. N Engl J Med 1979; 301: 361-363.

22. Madiedo G, Sciacca R, Hause L, Sasse E. Use of syringes containing dry (lyophilized) heparin in sampling blood for $\mathrm{pH}$ measurement and blood-gas analysis. Clin Chem 1982; 28: 1727-1729.

23. Hutchison AS, Ralston SH, Dryburgh FJ, Small M, Fogelman I. Too much heparin: possible source of error in blood gas analysis. Br Med J 1983; 287: 1131-1132.

24. Sauty A, Uldry C, Debétaz LF, Leuenberger P, Fitting JW. Differences in $\mathrm{PO}_{2}$ and $\mathrm{PCO}_{2}$ between arterial and arterialized earlobe samples. Eur Respir J 1996; 9: 186-189.

25. Muller-Plathe O, Heyduck S. Stability of blood gases, electrolytes and haemoglobin in heparinized whole blood samples: influence of the type of syringe. Eur J Clin Chem Clin Biochem 1992; 30: 349-355.

26. Biswas CK, Ramos JM, Agroyannis B, Kerr DNS. Blood gas analysis: effect of air bubbles in syringe and delay in estimation. $\mathrm{Br}$ Med $J$ 1982; 284; 923-927. 